\title{
Comparação entre a política florestal do Brasil e da Columbia Britânica (Canadá)*
}

\section{Alexandre Nascimento de Almeida**, Karina Vieira Gonçalves}

Faculdade UnB de Planaltina. Universidade de Brasília (FUP/UnB). Área Universitária $\mathrm{n}^{\circ}$ 1. Vila Nossa Senhora de Fátima. Planaltina-DF. Brasil. (CEP 73300-000). **E-mail: alexalmeida@unb.br.

Resumo. A legislação florestal brasileira, considerada avançada para muitos autores, é o principal mecanismo de proteção das florestas. Todavia, a efetividade dessa legislação é questionada devido aos níveis alarmantes de desmatamento observados no território nacional. Alguns autores defendem que os instrumentos de comando e controle, principal instrumento de política pública na qual o Código Florestal brasileiro (Lei no 12.651/2012) está fundamentado propicia a criação de leis sem perspectiva para a sua efetiva aplicação. Por seu turno, o Canadá é identificado como um dos líderes mundiais em gestão sustentável de florestas, porém os instrumentos de política pública aplicados no Canadá são os mesmos observados no Brasil. Este estudo compara a aplicação das legislações florestais entre o Brasil e a Columbia Britânica (Canadá). Os resultados deste estudo mostram que a falta de regularização fundiária no Brasil compromete o controle do estado sob o território e consequentemente a efetividade da aplicação da lei, principalmente em terras privadas. Ao passo que o controle efetivo observado nas províncias canadenses propicia o desenvolvimento de atividades econômicas em nível zero de desmatamento e auxilia a implementação efetiva de políticas públicas florestais.

Palavras-chave: Instrumentos de política pública; Situação florestal; Brasil; Canadá.

Abstract. Comparison between Brazil's and British Columbia's forest policy. The Brazilian forest legislation, which is considered advanced by many authors, is the major mechanism of forest protection. However, the effectiveness of this legislation has been questioned due to the alarming levels of deforestation observed in the national territory. Some authors stand out that the command and control instruments (main public policy instruments in which the Brazilian Forest Code is based on) allow the creation of laws with low compliance. On the other hand, Canada is identified as a world leader in sustainable forest management, although it has the same public policy instruments used in Brazil. This study compares the implementation of forest legislation in Brazil to the one observed in British Columbia (Canada). The results show that the lack of land tenure in Brazil compromises the State control over the territory and, consequently, interferes with the effectiveness of law enforcement,

Recebido:

19/12/2016

Aceito:

$27 / 06 / 2017$

Publicado:

30/06/2017

Acesso Aberto

Artigo completo

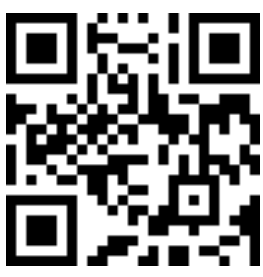

ORCID

(1) 0000-0002-9113-0729

Alexandre Nascimento de Almeida

(1) 0000-0002-9905-3334 Karina Vieira Gonçalves *Baseado no Trabalho de Conclusão do Curso de Bacharelado em Gestão Ambiental, da Universidade de
Brasília, Planaltina-DF, em 2015, da segunda autora. 
particularly on private land, whereas effective control observed in the Canadian provinces makes possible the development of economic activities to zero deforestation and assists in the effective implementation of forest policies.

Keywords: Public policy instruments; Forest situation; Brazil; Canada.

\section{Introdução}

A gestão ambiental, assunto tratado desde o início da década de 1970, tem sido debatida mundialmente em conferências internacionais na busca de encontrar objetivos globais e desenvolver mecanismos de política ambiental consorciados; entretanto, apesar do caráter comum conferido a gestão ambiental, ela correu por diferentes rumos em cada jurisdição devido as especificidades políticas, econômicas e culturais que configuram os diversos países (Magrini, 2001). A crescente pressão internacional tem impulsionado o desenvolvimento de mecanismos de gestão ambiental em todo o mundo. No Brasil, o principal efeito da pressão internacional para 0 desenvolvimento sustentável teve sua manifestação mais consistente por meio da Lei $\mathrm{n}^{\circ}$ 6.938/1981, que instituiu a Política Nacional do Meio Ambiente (PNMA) (Brasil, 1981; Barros et al., 2012).

Os instrumentos de política utilizados pela administração pública para alcançar os objetivos da PNMA são os de comando e controle (CC) e os econômicos ou de mercado (IM) (Andrade e Fasiaben, 2009). De fato, o instrumento de política ambiental mais utilizado é o de CC, esse busca a regulação pública por meio da aplicação de leis e normas. O CC, dentre outros aspectos, caracteriza-se pela restrição de atividades, controle do manejo de recursos naturais e especificação de tecnologias (Barros et al., 2012).

Apesar do CC ser o mecanismo de regulação mais usado pela administração pública brasileira, esse instrumento é criticado em vários aspectos e situações quanto a sua efetividade. Em geral, as críticas pautam-se ao exposto por Margulis (1996), onde discutiu os problemas ambientais prioritários em diferentes nações e da escolha dos mecanismos adequados para enfrentar tais problemas. Margulis (1996) afirmou que a eficácia dos instrumentos de CC depende da capacidade do Estado de assegurar o cumprimento da lei, demandando uma instituição eficaz que traduza na prática a aplicabilidade do comando e de uma entidade fiscalizadora que controle os atores sociais de forma efetiva, o que na realidade se constitui em um dos maiores desafios para os países, principalmente aqueles em desenvolvimento.

$\mathrm{Na}$ mesma linha de Margulis (1996), Barbieri (2007) explorou os diversos instrumentos de política pública ambiental e discorre acerca da sua eficácia. Para Barbieri (2007), uma das desvantagens dos instrumentos de CC é a necessidade de um aparato institucional oneroso. A criação de leis e normas ambientais sem sua devida aplicação constitui-se em uma das maiores ameaças ao desenvolvimento sustentável. De fato, o entendimento das principais falhas de aplicação da lei é necessário para a formação de um sistema político eficaz.

A legislação florestal brasileira, mais precisamente o Código Florestal, é fundamentada em instrumentos de CC, destacando a obrigatoriedade de preservação de áreas por meio da Reserva Legal (RL) e das Áreas de Preservação Permanente (APP). Os instrumentos de CC, por sua vez, apresentam problemas de irregularidade e não conformidade que colocam a efetividade da política pública em questionamento e comprometem a gestão florestal no Brasil (Sparovek, 2011). Por outro lado, a legislação florestal canadense, também fundamentada nos mesmos instrumentos, é referência mundial no que concerne à gestão sustentável de suas florestas, sugerindo uma comparação entre os dois países no intuito de entender os motivos que levam a política florestal 
canadense ser mais efetiva quando comparada com a brasileira.

Cashore (2004), ao comparar as políticas florestais entre diferentes jurisdições, alerta para os desafios considerando a enorme variação de aplicação dessas políticas em cada país, bem como as características distintas entre as formações florestais em diferentes países. Todavia, a busca pela comparação, conforme os melhores padrões mundiais, não permite apenas conhecer, aprender e copiar os melhores exemplos, mas sim envolve o conhecimento das vantagens competitivas de ambos os países (Almeida, 2010).

Assim, o objetivo do trabalho é comparar os instrumentos de política pública entre as legislações florestais brasileira e canadense e analisar a situação florestal desses países.

\section{Referencial teórico}

\section{Benchmarking ambiental}

O benchmarking nada mais é do que a busca pelas melhores práticas, sejam essas em serviços, processos ou produtos (Couto, 2013). Lovarato (2003) abordou o benchmarking sob a ótica da gestão ambiental. Para a autora, o benchmarking ambiental visa à melhoria contínua de práticas ambientais a partir de comparações com ênfase nos processos e resultados ambientais.

Dentro do cenário de políticas públicas ambientais, a comparação com os melhores exemplos disponíveis possibilita a avaliação da efetividade da política pública. Este processo deve ser encorajado, uma vez que a busca pelo aperfeiçoamento da gestão ambiental pode refletir em avanços significativos na gestão sustentável dos recursos naturais e, assim, trazer maior efetividade para a máquina pública.

Um estudo comparativo conduzido pelo professor Cashore (2004) revelou que as políticas florestais no Canadá são consideradas as mais rigorosas no mundo. O estudo comparou as políticas florestais canadenses com políticas florestais de 38 jurisdições e afirmou a soberania desse país no manejo sustentável dos recursos florestais. A efetividade da legislação florestal canadense fez com o que o país se posicionasse entre aqueles com maior área de florestas protegidas no mundo. A área com florestas protegidas no Canadá são maiores do que as áreas da Rússia e Brasil, apesar desses dois países serem os maiores detentores de áreas florestais do mundo (FAO, 2015). O desenvolvimento da gestão florestal canadense o posiciona na categoria de líder mundial em certificação florestal por terceiros.

\section{Código Florestal Brasileiro}

O primeiro Código Florestal no Brasil foi inaugurado no dia $1^{\circ}$ de abril de 1907, no Estado do Paraná, concedendo às "florestas protetoras" paranaenses a condição de "utilidade pública”. O Paraná, além de estabelecer normas para a exploração madeireira, como a estipulação de época para a efetuação de cortes rasos, responsabilizava-se pela demarcação das áreas de "florestas protetoras" e os proprietários de terra tinham o dever de notificar ao estado o ato de conversão de áreas florestais em campo (Carvalho, 2007). Em 1919, foi elaborado um projeto de lei na qual se exigia a recomposição de área derrubada por, no mínimo, 25\% de espécies de eucalipto. A ideia foi bem vista, pois o projeto de lei prometia dar fim a floresta "caótica" e "sem produtividade" para uma nova versão mais manejável e rentável. Nas palavras de Gubert Filho (2010):

\begin{abstract}
“[...] A indústria do pinho progrediu extraordinariamente, a ponto de a extração da araucária tornar-se desenfreada. [...] A partir de 1920, passou-se a dizimar imensas regiões florestadas do Segundo Planalto paranaense, para implantação da agricultura extensiva, denominadas "roças-de-toco", em vista da expansão da população sertaneja, quase sempre entregue a um "nomadismo atávico". Gubert Filho (2010)
\end{abstract}

Por meio do Decreto $n^{\circ}$ 23.793/1934 (Brasil, 1934), foi aprovada a primeira versão do Código Florestal brasileiro, sob o governo do presidente Getúlio Vargas, que, apesar da visão 
utilitarista concedida às florestas, foi resultado de uma preocupação crescente com a derrubada de áreas de vegetação nativa para a produção madeireira (Brasil, 1934; Garcia, 2012). Carvalho (2007) entende o Código Florestal de 1934 "como parte do esforço do Estado em modernizar, ordenar a produção e, consequentemente, controlar e ordenar o próprio território". Carvalho (2007) revela que o Código Florestal de 1934 não objetivava a plena proteção das florestas, mas a conservação da "cobertura florestal", pois o Código Florestal de 1934 possuía um viés mais produtivista do que preservacionista. Por exemplo, as florestas compostas majoritariamente por matas de araucárias (florestas homogêneas) podiam ser exploradas, desde que não houvesse formação de clareiras (art. 49, do CF de 1934). Já as florestas heterogêneas (florestas tropicais) eram subordinadas ao corte raso e a restituição florística podia dáse por espécies diferentes das abatidas, tudo isso com o intuito de "homogeneizar" as florestas para torná-las mais produtivas (art. 50, do CF de 1934).

Em 1965, foi editado um novo Código Florestal pela Lei $\mathrm{n}^{\circ}$ 4.771, de 15 de setembro de 1965, que, apesar das modificações, manteve os pressupostos e objetivos no Código Florestal de 1934. Porém, o foco do Código Florestal de 1965 foi a preservação dos recursos hídricos e a preservação de áreas de riscos das florestas protetoras, agora chamadas de Áreas de Preservação Permanente (APP) (Brasil, 1965; Garcia, 2012).

Em 1989, o Código Florestal passa por modificações, por meio da Lei $\mathrm{n}^{\circ}$ 7.803/1989, que estipulou novas faixas de APPs, considerando as dimensões dos cursos d'água, independentemente de estar em área rural ou urbana (Brasil, 1989; Silva et al., 2012).

As mudanças quanto às faixas de APPs ao longo de cursos hídricos deram-se pelas tragédias observadas em estados brasileiros devido à ocupação irregular de áreas de riscos, principalmente devido às grandes enchentes ocorridas nos anos de 1983 e 1989 no Estado de Santa Catarina. Estudos constataram que as regiões mais afetadas eram justamente aquelas que se localizavam mais próximas a cursos d'água e encostas de morros, deixando claro que uma faixa maior de APP evitaria as tragédias observadas (Silva et al., 2012).

Enquanto o Código Florestal de 1934 visava a conter o desmatamento desenfreado, resguardando o direito de exploração irrestrita para os imóveis particulares, o Código Florestal de 1965 revelava uma política intervencionista por parte do estado regulando o uso dos recursos florestais em propriedades privadas. Sobre o Código Florestal de 1965, Kengen (2001) destacou:

Comparada à norma de 1934, o novo Código Florestal apresenta um viés intervencionista, ao permitir ao Estado uma interferência direta e ostensiva na proteção às florestas, em defesa dos interesses coletivos. Dessa forma, o uso da propriedade fica restringido e subordinado ao interesse da coletividade, de tal forma que a função protetora da floresta, na propriedade privada, passa constituir restrição não indenizável. (Kengen, 2001, p. 24)

Após a implementação do Código Florestal de 1965, a legislação passa por ajustes que se tornaram as principais garantias de conservação florestal. São elas: a regulamentação das Áreas de Proteção Ambiental (APA) em 1981; a regulamentação da legislação sobre as Áreas de Preservação Permanente (APP) em 1989; e a regulamentação da Reserva Legal em 1998 (Garcia, 2012). Nas APAs, são previstas normas disciplinadoras de uso do solo e o seu descumprimento acarreta embargo das iniciativas irregulares e multa aos infratores. As APPs são áreas protegidas devido a sua função ambiental de preservar os recursos hídricos, a paisagem, a estabilidade geológica e a biodiversidade. A Reserva Legal, além de auxiliar a conservação e a reabilitação dos processos ecológicos, tem a função de assegurar o uso econômico de modo sustentável dos recursos naturais do imóvel rural. A delimitação da APP e da Reserva Legal passaram a ser determinadas pelo Código Florestal de 1965. 
As mudanças ocorridas no Código Florestal desde a sua implementação em 1934, apesar de certo cunho produtivista, visaram à preservação das florestas brasileiras frente ao desmatamento desenfreado que ameaçava comprometer os inúmeros serviços ecológicos oferecidos pelas florestas. Nesse período, a preocupação com o desmatamento era muito relacionada ao receio de faltar carvão, matéria-prima bastante usada pelas indústrias na época. Todavia, os objetivos do Código Florestal foram parcamente cumpridos. Os níveis de desmatamento continuaram a aumentar e apesar de todas as mudanças que o Código Florestal fora submetido, na maioria das regiões brasileiras, notam-se apenas remanescentes florestais do que um dia foi considerado Bioma, como no caso da Mata Atlântica. Por exemplo, analisando o efeito no desmatamento após a edição da Medida Provisória $\mathrm{n}^{\circ}$ 1.511/1996 (Brasil, 1996), que aumentou a área de Reserva Legal de $50 \%$ para $80 \%$ na Amazônia, Almeida et al. (2013) concluiu que essa medida mais restritiva não garantiu uma redução do desmatamento na região.

Para Carvalho (2007), a legislação florestal brasileira é considerada ampla e moderna para alguns, porém sofre do mal de não ser cumprida. A crescente pressão ambiental, originada nos calorosos debates internacionais ocorridos nos Estados Unidos e na Europa, impulsionou diversas mudanças na legislação ambiental brasileira, entretanto faltavam ao Brasil a estrutura necessária para implementação da nova legislação ambiental e grupos de pressão necessários para trazer praticidade a legislação (Carvalho, 2007; Sánchez, 2008).

\section{Código Florestal Canadense}

$\mathrm{O}$ estudo promovido pelo Instituto Canadense de Lei de Recursos (Canadian Institute of Resources Law - CIRL) traz uma análise minuciosa sobre o histórico de consolidação da gestão florestal nas províncias e territórios canadenses (Ross, 1997). A constituição canadense, seção 92(A) (Canada, 1867), concede às províncias o poder de propriedade e de controle legislativo sobre as suas florestas, restringindo o poder federal sobre a gestão florestal do país. O domínio da União sobre a gestão dos recursos florestais é baseado na propriedade de recursos florestais que pertencem ao governo, cujas áreas são concentradas majoritariamente nos Territórios do Noroeste e Yukon.

A legislação florestal provincial no Canadá passou por quatro estágios principais, até consolidar a gestão florestal sustentável no país. O primeiro estágio da legislação canadense (Regulation for Revenue Era), que se estendeu da metade ao fim do século XIX, foi caracterizado por um período de desmatamento florestal desenfreado. Um dos marcos desse período foi a concessão da posse de florestas e a implementação de políticas de licenciamento.

O segundo estágio (Conservation Era), que se estendeu do começo a metade do século $\mathrm{XX}$, caracterizou-se pela regulação do uso florestal para fins de aumento de lucro e receita do estado. A legislação florestal tinha a finalidade de proteger o uso contínuo dos recursos florestais de forma a não comprometer a oferta de madeira, assim como proteger as florestas contra incêndios e pestes.

O terceiro estágio da legislação florestal (Forest Management Era), que se estendeu da metade do século XX até os anos 1980, partiu dos compromissos estabelecidos nas Comissões Reais do país que recomendavam a adoção de políticas sustentáveis para alterar os sistemas de posse de florestas. Essa mudança na política partiu da preocupação com o desencadeamento da exploração florestal desenfreada devido a um sistema que facilitou licenças para o corte instituído no regime anterior.

O novo sistema de licenças de uso florestal procurava estimular a adoção de práticas sustentáveis pelos licenciados a partir da inclusão de incentivos fiscais e pela transferência de responsabilidades de uso sustentável para os licenciados. Apesar dessa mudança expressiva na gestão florestal, o setor industrial revelou grande relutância em assumir suas responsabilidades pelo uso sustentável dos recursos explorados. Essa relutância em 
assumir responsabilidades, somada à aplicação e ao monitoramento inadequado por parte da província prejudicou a transição do sistema de gestão florestal convencional para um sistema sustentável levando a sérios questionamentos a respeito da efetividade da nova política florestal.

Ao final do século XX, a legislação florestal provincial iniciou o seu quarto estágio (Sustainable Forest Management Era). Nesse momento a política florestal passa a reconhecer não apenas as funções econômicas das florestas, como também as dimensões ecológicas e sociais. Esse período marca a inclusão da participação pública na gestão florestal caracterizada pelos processos de consulta no estágio de planejamento da atividade.

A gestão sustentável do território canadense ocorre principalmente devido ao controle do Estado em seu território que propicia a fiscalização adequada das atividades que ocorrem. O processo de utilização das terras canadenses passa por uma série de etapas que permitem a identificação do enquadramento da atividade produtiva a ser realizada e dos mecanismos mais adequados para se alcançar a gestão sustentável. As práticas florestais que ocorrem no Canadá são baseadas no sistema de concessão florestal que demanda um plano de gestão desenvolvido por profissionais altamente qualificado para que seja garantido a gestão sustentável dos recursos diante fundamentação técnico-científica (McAfee e Malouin, 2008).

Mais de $90 \%$ das florestas canadenses estão sob o poder público. A gestão coordenada pelas províncias, com sua estrutura legal rígida e sistema eficaz de aplicação da lei, fazem do Canadá um país líder mundial em práticas florestais sustentáveis. O manejo florestal demanda o reflorestamento de toda a área florestal extraída logo após o fim das atividades produtivas fazendo com que o Canadá possua taxa zero de desmatamento (CCFM, 2011).

A gestão florestal do Canadá se apoia em rigorosos processos de planejamento e manejo em todos os níveis por todo o país - nacional, provincial, territorial e regional - além de contar com processos de consulta pública abrangentes, envolvendo povos indígenas, grupos ambientalistas, populações locais, grupos trabalhistas e outros grupos e indivíduos interessados em busca de pontos comuns e soluções mutuamente aceitas para lidar com os valores sociais, ambientais e econômicos das florestas (McAfee e Malouin, 2008).

\section{Metodologia}

A metodologia adotada foi a revisão bibliográfica de materiais publicados relacionados ao tema da pesquisa, bem como, o levantamento de dados estatísticos dos países analisados. Os materiais acadêmicos foram selecionados a partir do Google Scholar, Portal de Periódico da Capes e University of Toronto Library. Os dados estatísticos foram obtidos junto ao Instituto Brasileiro de Geografia e Estatística (IBGE), ao Ministério do Meio Ambiente (MMA), ao Instituto Brasileiro do Meio Ambiente e Recursos Naturais Renováveis (IBAMA), ao Instituto Chico Mendes de Conservação da Biodiversidade (ICMBio), Ministry of Natural Resources Canada (MNRC), Ministry of Forest of the Province of Ontario (MFPO), Mines and Lands of British Columbia (MLBC), Canadian Council of Forest Ministers (CCFM) e Natural Resources Canada (NRC).

Como cada província do Canadá possui o direito de legislar sobre as suas próprias florestas, a comparação entre os instrumentos legais entre os países foi representada pela gestão florestal canadense da província da Columbia Britânica, devido ser a província mais importante e com melhor desempenho de gestão florestal sustentável do país.

Portanto, a análise da contextualização legal dos países se constituiu no levantamento das normas florestais do Brasil e da província canadense de Columbia Britânica e no levantamento de dados governamentais referentes à gestão florestal em terras públicas e privadas do Brasil e do Canadá. Para a análise da situação florestal dos dois países foram apresentados dados referentes 
à área florestal, área protegida e área desmatada. Os dados referentes à situação florestal foram analisados por meio de estatística descritiva, com cálculos de porcentagem.

\section{Resultados e discussão}

\section{Instrumentos de política pública florestais do Brasil e do Canadá}

Os principais mecanismos de proteção e seus respectivos aspectos legais que fundamentam as políticas de comando e controle das florestas no Brasil e Canadá foram apresentados na Tabela 1.

A aplicação das medidas de proteção ambiental, conforme Tabela 1, apontaram que a legislação brasileira possui mecanismos de proteção mais abrangentes e específicos para as categorias ambientais indicadas. Além disso, a legislação florestal brasileira estabelece a obrigatoriedade de preservação dos ecossistemas categorizados como APP, tanto em áreas públicas quanto em áreas privadas. O Canadá, por outro lado, apresenta mecanismos de proteção apenas para duas das quatro categorias analisadas na Tabela 1. Os mecanismos de proteção para as categorias “zona ripária” e "ecossistemas sensíveis” são válidos apenas para unidades públicas, não se aplicando a obrigatoriedade de conservação em áreas privadas.

As normas florestais que se aplicam a unidades privadas no Brasil e Canadá variam enormemente, principalmente quanto às questões de preservação e mecanismos de controle. No Canadá, não foi identificado aspecto legal que obrigue o proprietário de terra a preservar parte do seu território, mas sim a geri-lo de forma sustentável. Conforme a Tabela 2, o uso dos recursos florestais em unidades privadas no Canadá deve ser realizado por meio de um Plano de Gestão que deve observar princípios de exploração sustentável. Dentro desse Plano é previsto o compromisso de gestão, declarações anuais das atividades realizadas, bem como, são realizadas inspeções ordinárias de um conselho como mecanismo de controle provincial para garantir a conformidade da gestão. Enquanto que no Brasil, são vários os mecanismos que atuam na preservação de recursos naturais em unidades privadas, tais como a manutenção de APPs e a preservação da ARL, que são porcentagens específicas de vegetação nativa para cada Bioma do país. O controle da manutenção da APP e ARL é realizado pelo Cadastro Ambiental Rural (CAR).

A respeito da gestão florestal em unidades públicas, observam-se similaridades e diferenças no sistema de manejo entre o Brasil e Canadá. Conforme a Tabela 2, tanto no Brasil quanto no Canadá, as atividades produtivas que se dão em florestas públicas ocorrem por meio de concessões florestais. $\mathrm{O}$ processo de concessão dá-se por meio de licitação, devendo observar uma gestão florestal sustentável.

No Canadá, o Plano de Gestão Sustentável de Florestas (Sustainable Forest Management Plan) deve ser realizado por profissionais ambientais altamente qualificados, cuja competência deve ser reconhecida perante o conselho florestal do município, tendo como objetivo assegurar um manejo adequado dos recursos naturais. No Brasil, o processo de licenciamento inclui o Contrato de Concessão Florestal, documento que, entre outras cláusulas, deve assegurar o manejo sustentável da atividade produtiva.

A diferença mais significante no processo de gestão em ambos os países é que no Canadá o plano de manejo deve obrigatoriamente providenciar a recomposição da cobertura vegetal perdida logo após a exploração florestal, pois o manejo florestal é feito por meio de corte raso da floresta. Tal fato não é encontrado nas Concessões Florestais do Brasil, pois o princípio do manejo de florestas tropicais no país permite retirar apenas pequeno número de árvores de modo a não afetar a estrutura da floresta e permitir a sua regeneração no longo prazo.

Dado as diferenças e similaridades da gestão florestal do Brasil e Canadá, o fato que chama maior atenção na comparação entre os dois países, e que parece determinar os fluxos de desmatamento e conservação de florestas, é 
a maior capacidade de controle do Estado na gestão dos recursos florestais no Canadá.

\section{Canadá}

\section{Situação florestal do Brasil e do}

A Tabela 3 apresentou a situação florestal dos países analisados. Apesar do Brasil possuir maior área florestal quando comparado ao Canadá (463 milhões de ha contra 347 milhões de ha), o Canadá possui maior área de floresta protegida (103 milhões de ha de área protegida no Canadá contra 75 milhões de ha protegidos no Brasil). A diferença de propriedade florestal também chama atenção; em torno de $90 \%$ das florestas canadenses estão sob poder das províncias e territórios canadenses, enquanto que no Brasil cerca de $67 \%$ das florestas estão sob poder da União. O setor privado também apresenta diferenças significantes. Apenas $6.2 \%$ das florestas canadenses pertencem ao poder privado, enquanto que $21.2 \%$ das florestas brasileiras estão sob esse domínio (SFB, 2013; Environment Canada, 2016).

Tabela 1. Proteção de áreas no Brasil e Canadá (Columbia Britânica) segundo critérios do Código Florestal Brasileiro.

\begin{tabular}{|c|c|c|c|c|}
\hline \multirow[b]{2}{*}{ Categoria } & \multicolumn{2}{|l|}{ Brasil } & \multicolumn{2}{|c|}{ Canadá } \\
\hline & Mecanismo de proteção & $\begin{array}{l}\text { Aspecto } \\
\text { legal }\end{array}$ & $\begin{array}{l}\text { Mecanismo de } \\
\text { proteção }\end{array}$ & Aspecto legal \\
\hline $\begin{array}{l}\text { Zonas ripárias } \\
\text { (Área de Preserva- } \\
\text { ção Permanente - } \\
\text { APP) }\end{array}$ & $\begin{array}{l}\text { Proteção de faixas margi- } \\
\text { nais de qualquer curso } \\
\text { d’água; faixas variam en- } \\
\text { tre } 30 \mathrm{~m} \text { e } 600 \mathrm{~m} \text { depen- } \\
\text { dendo da largura do } \\
\text { corpo hídrico a partir da } \\
\text { calha do leito regular. }\end{array}$ & $\begin{array}{l}\text { Código } \\
\text { Florestal, } \\
\text { art. } 4^{\circ}, \mathrm{I} .\end{array}$ & $\begin{array}{l}\text { Proteção de faixas } \\
\text { marginais de } \\
\text { qualquer curso } \\
\text { d'água; faixas de } 30 \\
\text { m a partir da calha } \\
\text { alta. Manutenção } \\
\text { e/ou criação de } \\
\text { Áreas de Realce }{ }^{1} \text {. }\end{array}$ & $\begin{array}{l}\text { Regulamento de } \\
\text { Áreas Ripárias } \\
\text { (Riparian Areas } \\
\text { Regulation). } \\
\text { Regulamento } n^{\circ} \\
\text { 376/2004, seção } \\
1 .\end{array}$ \\
\hline $\begin{array}{l}\text { Ecossistemas } \\
\text { sensíveis }\end{array}$ & $\begin{array}{l}\text { Proteção de veredas, } \\
\text { manguezais, bordas de } \\
\text { tabuleiros ou chapadas e } \\
\text { restingas }\end{array}$ & $\begin{array}{l}\text { Código } \\
\text { Florestal, } \\
\text { art. } 4^{\circ}, \text { VI, } \\
\text { VII, VIII e } \\
\text { XI. }\end{array}$ & $\begin{array}{l}\text { Proteção de áreas } \\
\text { úmidas (wetlands) }\end{array}$ & $\begin{array}{l}\text { Regulamento de } \\
\text { Áreas Ripárias } \\
\text { (Riparian Areas } \\
\text { Regulation); Re- } \\
\text { gulamento } n^{\circ} \\
\text { 376/2004, seção } \\
1\end{array}$ \\
\hline $\begin{array}{l}\text { Topos ou encostas } \\
\text { de morros }\end{array}$ & $\begin{array}{l}\text { Proteção de topo de } \\
\text { morros, montes, monta- } \\
\text { nhas e serras, com altura } \\
\text { mínima de } 100 \mathrm{~m} \text { e } \\
\text { inclinação média maior } \\
\text { que } 25^{\circ} \text {. }\end{array}$ & $\begin{array}{l}\text { Código } \\
\text { Florestal, } \\
\text { art. } 4^{\circ}, \text { IX. }\end{array}$ & $\begin{array}{l}\text { Nenhum mecanismo } \\
\text { esta categoria }\end{array}$ & de proteção para \\
\hline Altitude & $\begin{array}{l}\text { Proteção de áreas em } \\
\text { altitude superior a } 1.800 \\
\text { (mil e oitocentos) metros }\end{array}$ & $\begin{array}{l}\text { Código } \\
\text { Florestal, } \\
\text { art. } 4^{\circ}, \mathrm{X} \text {. }\end{array}$ & $\begin{array}{l}\text { Nenhum mecanismo } \\
\text { esta categoria }\end{array}$ & de proteção para \\
\hline $\begin{array}{l}\text { Área de Reserva } \\
\text { Legal }\end{array}$ & $\begin{array}{l}\text { Manutenção de área com } \\
\text { cobertura vegetal nativa } \\
\text { em propriedade privada } \\
\text { variando entre } 20 \% \text { a } \\
80 \% \text {. }\end{array}$ & $\begin{array}{l}\text { Código } \\
\text { Florestal } \\
\text { art. } 12 .\end{array}$ & $\begin{array}{l}\text { Nenhum mecanismo } \\
\text { centual de manutençãc } \\
\text { getal em terras privada }\end{array}$ & $\begin{array}{l}\text { estabelece per- } \\
\text { de cobertura ve- } \\
\text { as. }\end{array}$ \\
\hline
\end{tabular}

\footnotetext{
${ }^{1}$ Áreas de Realce (Enhancement Area) ligam os ecossistemas aquáticos aos ecossistemas terrestres, incluindo tanto a mata ciliar existente quanto a vegetação ripária potencial e as vegetações terrestres que exercem influência no corpo hídrico. Os limites da faixa de Áreas de Realce são determinados por um profissional altamente qualificado responsável pela confecção do relatório de avaliação (Canada, 2004).
} 
Fonte: Brasil (Código Florestal, Lei nº 12.651/2012); Canada (Riparian Areas Regulation, 2004).

Tabela 2. Gestão Florestal em Unidades Públicas no Brasil e Canadá (Columbia Britânica).

\begin{tabular}{|c|c|c|}
\hline \multicolumn{3}{|c|}{ Brasil } \\
\hline Aspecto Legal & Comando & Controle \\
\hline $\begin{array}{l}\text { Lei } n^{0} 11.284 \text {, de } 2 \text { de março } \\
\text { de } 2006 \text {. }\end{array}$ & $\begin{array}{l}\text { Realizar a gestão florestal para a } \\
\text { produção sustentável em } \\
\text { consonância com os princípios } \\
\text { da lei em questão }\end{array}$ & $\begin{array}{l}\text { Concessão florestal por meio de } \\
\text { licenciamento; fiscalizações } \\
\text { ordinárias; auditorias florestais e } \\
\text { relatórios anuais de atividades. }\end{array}$ \\
\hline \multicolumn{3}{|c|}{ Canadá } \\
\hline Aspecto Legal & Comando & $\begin{array}{l}\text { Controle } \\
\end{array}$ \\
\hline $\begin{array}{l}\text { Lei de Práticas Florestais e } \\
\text { Pastoris, de } 21 \text { de novembro } \\
\text { de } 2002 \text { (Forest and Range } \\
\text { Practices Act). }\end{array}$ & $\begin{array}{l}\text { Realizar a gestão florestal de } \\
\text { unidades públicas de forma a } \\
\text { propiciar a exploração a longo } \\
\text { prazo e a saúde das florestas. }\end{array}$ & $\begin{array}{l}\text { Concessão florestal, licenças e } \\
\text { acordos para a exploração; } \\
\text { relatórios anuais de atividades; } \\
\text { recomposição da cobertura } \\
\text { florestal imediata e inspeções do } \\
\text { conselho. }\end{array}$ \\
\hline
\end{tabular}

Fonte: Brasil (Lei nº 11.284/2006); Canada (Forest and Range Practices Act, 2002).

Tabela 3. Situação florestal no Brasil e Canadá.

\begin{tabular}{|c|c|c|c|c|}
\hline & \multicolumn{2}{|c|}{ Brasil } & \multicolumn{2}{|c|}{ Canadá } \\
\hline & Área (ha) & $\%$ & Área (ha) & $\%$ \\
\hline Área total do país & 851.576 .700 & $100,00 \%$ & 998.467 .000 & $100 \%$ \\
\hline Área florestal & 463.000 .000 & $54,00 \%$ & 347.575 .750 & $35 \%$ \\
\hline \multirow[t]{2}{*}{ Área florestal protegida } & 75.486 .877 & $16,00 \%$ & 103.664 .500 & $30 \%$ \\
\hline & \multicolumn{4}{|c|}{ Propriedade florestal } \\
\hline Governo federal & 308.000 .000 & $67,00 \%$ & 5.561 .212 & $1,60 \%$ \\
\hline Província/território & - & - & 266.243 .024 & $90,00 \%$ \\
\hline População nativa & 109.813.180 & $24,00 \%$ & 6.951 .515 & $2,00 \%$ \\
\hline Entidade privada & 98.480 .227 & $21,27 \%$ & 21.549 .696 & $6,20 \%$ \\
\hline
\end{tabular}

Fonte: SFB (2013); Environment Canada (2016).

A grande questão que gira em torno da propriedade florestal observada nos dois países é que no Canadá, diferentemente do Brasil, os dados de área florestal são bastante consolidados, o que possibilita a identificação de propriedade de $100 \%$ das florestas canadenses. Já no Brasil, o Cadastro Nacional de Florestas Públicas ainda se encontra em fase de identificação e consolidação, o que não permite uma visualização exata da situação das florestas públicas. Os dados provenientes do setor privado no Brasil são ainda mais incertos, pois as áreas florestais localizadas em terras privadas foram identificadas a partir de dados coletados por meio de questionários declaratórios do IBGE (IBGE, 2015), o que oferece um enorme grau de incerteza quanto à veracidade da estatística. Enquanto no Canadá o controle do estado permite a total identificação da cobertura florestal, tanto em unidades públicas quanto privadas, no Brasil o primeiro passo para cadastramento de florestas privadas foi dado apenas em 2012, por meio da instituição do CAR.

A Tabela 4 apresenta a porcentagem de desmatamento no período de 1990 a 2011, no Brasil e no Canadá. O desmatamento ocorrido no Canadá durante 
esse período foi nulo. Os principais fatores que corroboram para essa situação decorrem da concentração de propriedade florestal sob domínio público, associado com um sistema de gestão efetivo. Como grande parte das florestas canadenses estão sob domínio da província, as atividades econômicas que envolvem as explorações desse recurso caem sob o regime de concessão florestal canadense, cujo processo de manejo impõe a recomposição da área florestal explorada logo após a atividade.

Tabela 4. Evolução do desmatamento no Brasil e Canadá entre 1990 a 2011.

\begin{tabular}{lcc}
\hline País & Área de floresta \% do território & \% de evolução 1990 - 2011 \\
\hline Brasil & $62 \%$ & $-9,60 \%$ \\
Canadá & $34 \%$ & $0,00 \%$ \\
\hline
\end{tabular}

Fonte: FAO (2015).

Por outro lado, o Brasil apresenta uma taxa de desmatamento significante. Como mencionado anteriormente, o Estado brasileiro carece de mecanismos de controle sobre o território nacional. Os impasses latifundiários que levam a dados incertos sobre o sistema de posse de floresta não permite que o estado possa controlar os atores de forma eficiente e tampouco impor que os mecanismos de preservação florestal, principalmente em unidades privadas, seja de fato acolhido pelo público de interesse.

\section{Conclusões}

Embora o manejo florestal no Canadá seja realizado por meio do corte raso, seguido pelo reflorestamento, o controle do estado permite a observância da lei e, consequentemente, faz com que haja a sustentabilidade de suas florestas mantendo o nível de desmatamento praticamente nulo.

No Brasil, além da maior complexidade do manejo florestal, devido à diversidade das florestas tropicais, o estado não possui aparato para regular e muito menos fomentar a atividade florestal, tornando essa atividade pouco atrativa e incentivando a conversão das florestas nativas em áreas para a pecuária e agricultura.

Um dos principais motivos para a situação de desequilíbrio florestal no território brasileiro é a falta de regularização fundiária que não permite o controle efetivo do estado para assegurar a observância da legislação florestal, comprometendo a eficácia de aplicação de políticas públicas, principalmente no contexto privado. Entretanto, nota-se avanços no país, por meio de tentativas de regularização fundiária e crescimento das áreas sob concessão florestal, bem como a evolução no controle da lei decorrente da implementação do CAR.

A gestão florestal canadense, considerada uma das melhores gestões mundiais, propicia o desenvolvimento de atividades econômicas em nível zero de desmatamento por meio de concessões florestais para a iniciativa privada, devido, principalmente, ao controle efetivo das províncias que auxilia na implementação efetiva de políticas públicas.

\section{Declaração de conflito de interesses}

Os autores declaram não haver conflito de interesses.

\section{Referências}

Almeida, A. N.; Angelo, H.; Silva, J. C. G. L.; Soares, P. R. C.; Kanieski, M. R. Efetividade do aumento da área de Reserva Legal por meio de instrumento legal na taxa de desmatamento da Amazônia Brasileira. Floresta e Ambiente, 
v. 20, n. 2, p. 143-148, 2013. http://dx.doi.org/10.4322/floram.2013.012

Almeida, A. N. Comparação entre a competitividade do Brasil e Canadá para produção de madeira serrada. Curitiba: Universidade Federal do Paraná, 2010. (Tese de doutorado). Disponível em: <http://www.floresta.ufpr.br/ defesas/pdf_dr/2011/t300_0340-D.pdf>. Acesso em: 25 out. 2016.

Andrade, D. C.; Fasiaben, M. C. R. A utilização dos instrumentos de política ambiental para a preservação do meio ambiente: o caso dos pagamentos por serviços ecossistêmicos (PSE). Economia Ensaios, v. 24, n. 1, p. 113-133, 2009. Disponível em: <http://www.seer.ufu.br/ index.php/revistaeconomiaensaios/article/view/ 2223/4807>. Acesso em: 25 out. 2016.

Barbieri, J. C. Gestão ambiental empresarial: conceitos modelos e instrumentos. 2. ed. São Paulo: Saraiva, 2007.

Barros, D. A.; Borges, L. A. C.; Nascimento, G. O.; Pereira, J. A. A.; Rezende, J. L. P.; Alan Silva, R. Breve análise dos instrumentos da política de gestão ambiental brasileira. Política e Sociedade, n. 22, p. 155-179, 2012. http://dx.doi.org/10.5007/2175-7984.2012v11 n22p155

Brasil. Decreto $n^{0}$ 23.793, de 23 janeiro de 1934. Approva o codigo florestal que com este baixa. Disponível em: $<$ http://www.planalto.gov.br/ccivil_03/decreto/1 930-1949/D23793impressao.htm>. Acesso em: 25 out. 2016.

Brasil. Lei $\mathrm{n}^{\mathrm{o}}$ 4.771, de 15 de setembro de 1965. Institui o novo Código Florestal. Disponível em: $<$ http://www.planalto.gov.br/ccivil_03/leis/L47 71impressao.htm>. Acesso em: 25 out. 2016.

Brasil. Lei $\mathbf{n}^{\circ} \mathbf{6 . 9 3 8}$, de 31 de agosto de 1981 . Dispõe sobre a Política Nacional do Meio Ambiente, seus fins e mecanismos de formulação e aplicação, e dá outras providências. Disponível em: <http://www.planalto.gov.br/ ccivil_03/leis/L6938compilada.htm>. Acesso em: 25 out. 2016.

Brasil. Lei $\mathbf{n}^{\mathbf{0}} \mathbf{7 . 8 0 3}$, de 18 de julho de 1989 . Altera a redação da Lei $\mathrm{n}^{\circ} 4.771$, de 15 de setembro de 1965, e revoga as Leis $n^{\circ} \mathrm{s} 6.535$, de 15 de junho de 1978, e 7.511, de 7 de julho de 1986 . Disponível em: $<$ http://www.planalto.gov.br/ccivil_03/leis/L78 03.htm>. Acesso em: 25 out. 2016.

Brasil. Medida Provisória $\mathbf{n}^{0} \mathbf{1 . 5 1 1}$, de 25 de julho de 1996. Dá nova redação ao art. 44 da Lei $n^{\circ}$ 4.771, de 15 de setembro de 1965, e dispõe sobre a proibição do incremento da conversão de áreas florestais em áreas agrícolas na Região Norte e na parte Norte da Região Centro-Oeste, e dá outras providências. Disponível em: <http://www.planalto.gov.br/ ccivil_03/mpv/Antigas/1511.htm>. Acesso em: 25 out. 2016.

Brasil. Lei $\mathbf{n}^{\mathbf{0}}$ 11.284, de 2 de março de 2006. Dispõe sobre a gestão de florestas públicas para a produção sustentável; institui, na estrutura do Ministério do Meio Ambiente, o Serviço Florestal Brasileiro-SFB; cria o Fundo Nacional de Desenvolvimento Florestal FNDF; altera as Leis $n^{\circ} \mathrm{s} 10.683$, de 28 de maio de 2003, 5.868, de 12 de dezembro de 1972, 9.605, de 12 de fevereiro de 1998, 4.771, de 15 de setembro de 1965, 6.938, de 31 de agosto de 1981, e 6.015, de 31 de dezembro de 1973; e dá outras providências. Disponível em: <http://www.planalto.gov.br/ccivil_03/_ato2004 -2006/2006/lei/l11284.htm>. Acesso em: 25 out. 2016.

Brasil. Lei $\mathbf{n}^{0}$ 12.651, de 25 de maio de 2012. Dispõe sobre a proteção da vegetação nativa; altera as Leis $\mathrm{n}^{\circ} \mathrm{s}$ 6.938, de 31 de agosto de 1981, 9.393, de 19 de dezembro de 1996, e 11.428, de 22 de dezembro de 2006; revoga as Leis $\mathrm{n}^{\circ} \mathrm{s} 4.771$, de 15 de setembro de 1965, e 7.754, de 14 de abril de 1989, e a Medida Provisória $\mathrm{n}^{0}$ 2.166-67, de 24 de agosto de 2001; e dá outras providências. Disponível em: <http://www.planalto.gov.br/ccivil_03/_Ato201 1-2014/2012/Lei/L12651compilado.htm>.

Acesso em: 25 out. 2016.

Canada. British North America Act 1867. Disponível em: <http://www.thecanadian encyclopedia.ca/en/article/british-northamerica-act-1867-document>. Acesso em: 25 out. 2016.

Canada. Riparian Areas Regulation. 2004. Disponível em: <http://www.bclaws.ca/civix/ document/id/complete/statreg/376_2004>.

Acesso em: 25 out. 2016.

Canada. Forest and Range Practices Act. 2002. Disponível em: <http://www.bclaws.ca/ civix/document/id/complete/statreg/02069_01>. Acesso em: 25 out. 2016.

CCFM - Canadian Council of Forest Ministers. Forest Monitoring and Compliance in Canada. Sustainable Forest Management in Canada. 2011. Disponível em: $<$ http://www.sfmcanada.org/en/forestproducts/legal-forest-products>. Acesso em: 25 out. 2016.

Carvalho, E. B. Legislação florestal, território e modernização: o caso do Estado do Paraná 1907-1960. Anais do XXIV Simpósio Nacional 
de História, 2007. Disponível em: $<$ http://snh2007.anpuh.org/resources/content/an ais/Ely Bergo de Carvalho.pdf>. Acesso em: 25 out. 2016.

Cashore, B. How Canada compares. Ottawa: Forest Products Association of Canada, 2004. Disponível em: <http://www.fpac.ca/ publications/2004_HowCanadaCompares.pdf > . Acesso em: 25 out. 2016.

Couto, H. M. S. Benchmarking na gestão de unidades de saúde: estudo de caso na Fisioterapia do Serviço de Medicina Física e Reabilitação do Hospital de Braga. Minho: Universidade do Minho, 2013. (Dissertação de Mestrado). Disponível em: $<$ http://repositorium.sdum.uminho.pt/bitstream/ 1822/25871/1/TESE_HugoCouto.pdf $>$. Acesso em: 25 out. 2016.

Environment Canada. Canada's Protected Areas. Gatineau: Environment Canada, 2016. Disponível em: <https://www.ec.gc.ca/ indicateurs-indicators/A1570B00-E7C5-4A6A9485-98435F041A33/CanadasProtected Areas_EN.pdf>. Acesso em: 25 out. 2016.

FAO - Food and Agriculture Organization of the United Nations. Global forest resource assessment. 2015. Disponível em: $<$ http://www.fao.org/3/a-i4808e.pdf $>$. Acesso em: 25 out. 2016.

Garcia, Y. M. O Código Florestal Brasileiro e suas Alterações no Congresso Nacional. Revista Geografia em Atos - GEOATOS, v. 1, n. 12, 2012. Disponível em: $<$ http://revista.fct.unesp.br/index.php/geografiae matos/article/view/1754>. Acesso em: 25 out. 2016.

Gubert Filho, F. A. O desflorestamento do Paraná em um século: Reforma Agrária e Meio Ambiente: teoria e prática no Estado do Paraná. Curitiba: Instituto de Terras, Cartografia e Geociências, 2010.

IBGE - Instituto Brasileiro de Geografia e Estatística. Indicadores de desenvolvimento sustentável. Rio de Janeiro: IBGE, 2015. Disponível em: <http://biblioteca.ibge.gov.br/ visualizacao/livros/liv94254.pdf>. Acesso em: 25 out. 2016.

Kengen, S. A política florestal brasileira: uma perspectiva histórica. Anais do I Simpósio Ibero-Americano de Gestão e Economia Florestal, Porto Seguro, 2001. Disponível em: $<$ http://www.ipef.br/publicacoes/stecnica/nr34/c onvidados.pdf $>$. Acesso em: 25 out. 2016.
Lovarato, M. L. A. As vantagens do benchmarking ambiental. Revista Produção, $\begin{array}{llll}\text { v. } 4, & \text { n. 2, } & \text { p. 1-17, }\end{array}$ https://dx.doi.org/10.14488/1676-1901.v4i2.307

Magrini, A. política e gestão ambiental: conceitos e instrumentos. Revista Brasileira de Energia, v. 8, n. 2, p. 1-8, 2001. Disponível em: <http://new.sbpe.org.br/wp-content/themes/ sbpe/img/artigos_pdf/v08n02/v08n02a7.pdf>. Acesso em: 25 out. 2016.

Margulis, S. A regulamentação ambiental: instrumentos e implementação. Rio de Janeiro: Instituto de Pesquisa Econômica Aplicada, 1996. (Texto para discussão, 437). Disponível em: <http://www.ipea.gov.br/agencia/images/ stories/PDFs/TDs/td_0437.pdf>. Acesso em: 25 out. 2016.

McAfee, B.; Malouin, C. Implementing ecosystem-based management approaches in Canada's forests: a science-policy dialogue. Ottawa: Natural Resources Canada, 2008. Disponível em: <http://www.cfs.nrcan.gc.ca/ pubwarehouse/pdfs/28282.pdf $>$. Acesso em: 25 out. 2016.

Ross, M. M. A history of forest legislation in Canada 1867-1996. Alberta: Canadian Institute of Resources Law, 1997.

Sánchez, L. E. Avaliação de impacto ambiental: conceitos e métodos. São Paulo: Oficina de Textos, 2008.

SFB - Serviço Florestal Brasileiro. Florestas do Brasil em Resumo 2013. Brasília: Ministério do Meio Ambiente, 2013. Disponível em: $<$ http://www.florestal.gov.br/snif/images/Public acoes/florestas_do_brasil_em_resumo_2013_at ualizado.pdf>. Acesso em: 25 out. 2016.

Silva, F.; Foleto, E. M.; Robaina, L. E. S. Áreas de preservação permanente e áreas de risco ambiental: quando as duas terminologias se concentram na mesma tragédia. $\mathrm{O}$ caso do Morro do Baú em Santa Catarina e da Região Serrana do Estado do Rio de Janeiro. Geonorte, v. 1, n. 4, p. 459-473, 2012. Disponível em: <http://www.periodicos.ufam.edu.br/revistageonorte/article/download/1848/1726>. Acesso em: 25 out. 2016.

Sparovek, G.; Barretto, A.; Klug, I.; Papp, L.; Lino, J. A revisão do Código Florestal Brasileiro. Revista Novos Estudos, v. 89, p. 111-135, 2011. http://dx.doi.org/10.1590/ S0101-33002011000100007

Informação da Licença: Este é um artigo Open Access distribuído sob os termos da Licença Creative Commons Attribution, que permite uso irrestrito, distribuição e reprodução em qualquer meio, desde que a obra original seja devidamente citada. 